\title{
Ecos de Messiaen em Almeida Prado: Estudo de Caso no 4o Movimento das Cartas Celestes XV
}

\author{
Echoes of Messiaen in Almeida Prado: \\ "Cartas Celestes XV", 4th movement - a Case Study
}

\begin{abstract}
Aleyson Scopel
Universidade Federal do Rio de Janeiro

Aleysonscopel@hotmail.com
\end{abstract}

\author{
Ana Paula da Matta Machado Avvad \\ Universidade Federal do Rio de Janeiro \\ paulamtt@globo.com
}

\begin{abstract}
Resumo: O presente trabalho mostra a influência de Messiaen presente na obra de Almeida Prado (1943-2010), através de um estudo de caso do quarto movimento das Cartas Celestes XV (2009) Constelação da Ave do Paraíso (Avis Indica), para piano. Compostas por 18 obras, das quais 15 para piano, as Cartas Celestes são consideradas pelo próprio compositor uma das obras mais importantes de sua carreira e um ponto de reflexão sobre a evolução de sua escrita. Segundo o próprio testemunho do compositor brasileiro, a influência de Messiaen (1908-1979), um de seus professores em Paris, na sua produção musical, está presente na noção de autonomia do ritmoe no alargamento do espaço sonoro, visando a produção e a organização formal da son oridade colorida. A fascinação pelos pássaros também é compartilhada por ambos compositores e representa a temática central do movimento Constelação da Ave do Paraíso (Avis Indica).
\end{abstract}

Palavras-chave: Almeida Prado; Messiaen; Cartas Celestes; Piano.

\begin{abstract}
The present article reveals the influence of Messiaen in the work of Almeida Prado (1943-2010), through the case study of the fourth movement of Cartas Celestes XV (2009) - The Bird of Paradise Constellation (Avis Indica), for piano. It is part of a cycle composed of 18 volumes, from which 15 are w ritten for piano, and regarded by the composer as one of his most important works. According to Prado's own testimony, the influence of Messiaen (1908-1979), one of his teachers in Paris, in his musical production, is present in the notion of rhythmic autonomy and the stretch of his sound space. He also shares with him a fascination with birds, which is the central theme of the movement.
\end{abstract}

Keywords: Almeida Prado; Messiaen; Cartas Celestes; Piano. 


\section{1 - Almeida Prado e o Transtonalismo}

José Antônio de Almeida Prado (1943-2010) é considerado um dos mais importantes compositores brasileiros, tendo deixado um legado composicional que ultrapassa 600 composições. O compositor atravessou diferentes fases estéticas e costumava dividir sua produção artística em períodos, enfatizando, porém, que são interdependentes e passíveis de serem reagrupados diferentemente. Hideraldo Grosso (1997, p. 191) estabelece a divisão em sete fases: Fase da Infância (1952-1959); Fase do Nacionalismo (1960-1965); Fase Autodidata ou Atonal-livre (1965-1969); Fase de estudos na Europa com Boulanger e Messiaen (1969-1973); Fase da Ecologia, Astronomia, Fauna e Flora (1973-1983); Fase do Pós-modernismo ou Místico-religiosa (1983-1993); e Fase Tonal-livre (1993-2010).

Na fase de estudos na Europa, Almeida Prado frequentou, em Paris, as classes de Nádia Boulanger (1887-1979) e Olivier Messiaen (1908-1992). Boulanger e Messiaen representavam, para os que buscavam aperfeiçoamento na França, o melhor de dois universos contrastantes: "a primeira era considerada formalista de feição acadêmica; o segundo, mais afeito às práticas não-ortodoxas, sem contar que houvera sido o mestre dos compositores de Darmstadt, como Stockhausen e Boulez" (Salles 2005, p. 187).

A vasta produção de Almeida Prado abordou diferentes temáticas. Merecem destaque a temática ecológica, inspirada pela fauna e flora, e a astrológica, que mostra seu olhar sobre o céu do Brasil e inspirou a série de Cartas Celestes.

Inseridas entre as obras mais importantes de sua carreira, as Cartas Celestes são um ciclo de dezoito obras, das quais quinze para piano solo. Resultantes de fecundos períodos e, em suas palavras, "responsáveis para um novo posicionamento [...] diante da utilidade da minha música" (Almeida Prado 1985, p.2), nelas, Almeida Prado empregou de todas as formas imagináveis a exploração dos timbres e ressonâncias do piano, com grande influência dos ideais estéticos de Messiaen.

Após estrear o primeiro volume das Cartas Celestes com sucesso na Europa em 1974, Prado fez a primeira audição no Brasil em São Paulo, na Universidade de Campinas. Estava presente na ocasião o musicólogo Yulo Brandão que, ao ouvir as Cartas Celestes, proclamou que Almeida Prado havia criado um novo sistema de compor, ao qual ele denominou de Transtonalismo.

O transtonalismo veio a ser a maior inovação de toda a carreira de Almeida Prado e a técnica crucial e dominante utilizada nas Cartas Celestes. Almeida Prado descreve o "Transtonalismo" da seguinte forma: 
O Transtonalismoé a utilização consciente das funções harmônicas de um acorde através dos harmônicos superiores e inferiores de uma fundamental. Você aproveita a ressonância dos harmônicos de uma fundamental para valorizar determinada parcial ou parciais. Eu encontrei uma forma de utilizar a tradição da harmonia com a liberdade de minha linguagem. (Almeida Prado apud Gazzaneo 2011, p. 216).

\section{Carole Gubernikoff acrescenta:}

[Almeida Prado] considera esta técnica semelhante, em seus princípios, à empregada pelos compositores da escola espectral, cujos maiores representantes são Tristan Murail e Gérard Grisey, ambos contemporâneos da classe de composição de Messiaen [...] Este conceito [...] consiste na construção de uma 'passagem' harmônico-timbrística de um modelo de espectro a outro. $\mathrm{O}$ transtonalismo de Almeida Prado combina a necessidade de uma escuta dirigida pelos baixos, que conduzem a harmonia no sentido tradicional, com vários recursos técnicos utilizados principalmente nos anos 70 e especial atenção à textura. (Gubernikoff apud Salles 2005, p. 205, grifo nosso).

Com o transtonalismo, Almeida Prado foi capaz de obter um alargamento de seu espaço sonoro: "Eu utilizei o excesso de ressonâncias, por exemplo, em uma insistência em determinado acorde, repetindo ele. Alargava-o. Foi algo que Beethoven fez, no tonal. Eu queria fazer no transtonal. Ou no atonal" (Almeida Prado apud Tafarello 2010, p. 273). Essa insistência na repetição de acordes é essencial, na opinião de Almeida Prado, para que a música tenha a ideia de espiral, algo que a seu ver não era possível com a música serial.

\section{2 - Cartas Celestes XV}

Compostas em 2009, as Cartas Celestes XV fazem parte do seu último período composicional, cuja característica principal é a total liberdade, realizando uma síntese de todos os períodos anteriores, adicionando material tonal livre e de multiplicidade de texturas e timbres. As Cartas Celestes XV: O Universo em expansão têm como tema central a formação e a expansão do universo e são divididas em seis movimentos: A Estrela GRB090423, Nebulosa do Esquimó, Constelação de Pictoris (Pintor) \& Planeta Extra-Solar, Constelação da Ave do Paraíso (Avis Indica), Nebulosa Planetária NGC3195 e Vento Solar. Nas Cartas Celestes $X V$, podemos observar diversas influências de Messiaen no quarto movimento. 


\section{1 - Constelação da Ave do Paraíso (Avis Indica)}

Em entrevista de 2007 a Tadeu Moraes Taffarello (2010), Almeida Prado reflete sobre a influência de Olivier Messiaen em sua carreira e modo de compor. Messiaen, que fora um de seus professores em Paris, prezava pela liberdade estilística de seus discípulos. Por isso mesmo, nenhum deles se limitou a imitar o estilo do compositor, constituindo, dessa forma, um grande tributo à qualidade de seu ensino.

Para Almeida Prado, no aprendizado com Messiaen, a principal contribuição foi a noção da autonomia do ritmo: "Porque você pode partir de um ritmo, desassociá-lo da melodia e associá-lo a si próprio. Essa era a visão que Messiaen tinha já do total rítmico, uma entidade independente, o ritmo em si próprio" (Almeida Prado apud Tafarello 2010, p. 272).

Ainda de acordo com Almeida Prado, na mesma entrevista, a influência de Messiaen também se faz presente no alargamento do espaço sonoro de sua música. A perspectiva que Messiaen abriu para a sistemática utilização da sonoridade como força propulsora de estruturas formais está diretamente ligada à ideia do transtonalismo. As técnicas composicionais do compositor francês sobretudo no campo da harmonia e da orquestração - visam a produção e organização formal de "cores" sonoras. "A técnica da 'ressonância acrescentada', em particular, consegue aproximar, até confundi-las, as dimensões harmônicas e sonorísticas, de modo que os acordes se tornam 'entidades sonoras'". (Guigue 2001, s/p). Já a técnica do Som-cor, termo assinalado por Messiaen (le son-couleur) que representava o modo intelectual ou interior de associar sons a cores, é por Almeida Prado absorvida de maneira metafórica e poética.

Almeida Prado dividiu ainda com Messiaen sua fascinação pelos pássaros. Seu pai era um colecionador de pássaros e, por isso, desde sua infância, teve contato com esse mundo. A primeira referência a corpos celestes nomeados após aves é encontrada na "Constelação do Pavão" (vide Exemplo 1), nas Cartas Celestes II.

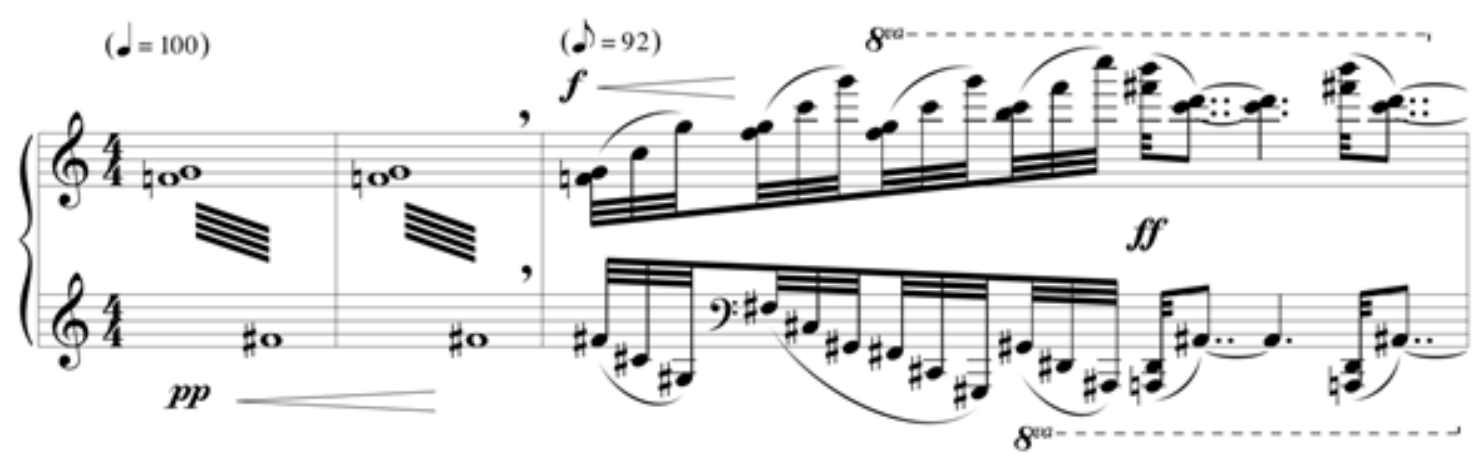

Exemplo 1: Almeida Prado, Cartas Celestes II (Constelação do Pavão), c. 1-3

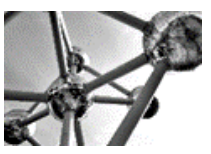


Almeida Prado, em sua tese, explica que tentou imitar nessa constelação, com os acordes-alfabeto, "os gritos da ave e a demonstração abusiva da estonteante beleza de sua plumagem" (Almeida Prado 1985, p. 51).

Tais acordes fazem parte do catálogo de 24 acordes do alfabeto grego, apresentado nas Cartas Celestes I. Os seis primeiros volumes das Cartas Celestes, compostos entre 1974 e 1982, utilizam esses acordes ${ }^{1}$. Em sincronia entre temática e ideal sonoro, tem-se mais uma vez os acordes gregos como princípio composicional da "Constelação da Ave do Paraíso - Avis Indica", que posteriorm en te ficou conhecida como Apus. Sobre o termo ave do paraíso, explica White:

Os caçadores que, no século 16, negociaram os primeiros espécimes com os europeus, muitas vezes removiam as asas e as pernas dos pássaros de modo a ressaltar ao máximo sua plumagem exótica. Isso inspirou a ideia de que eram, literalmente, aves divinas, pairando nos céus sem jamais tocar a terrae extraindo seus alimentos das névoas paradisíacas² (White 2012, p. 70).

No "jardim de estrelas" (indicação no início do movimento) sugerido por Prado, tem-se, na ordem em que aparecem, os seguintes acordes transtonais: Beta $(\beta)$, Gama $(\gamma)$, Delta $(\delta)$, Eta $(\eta)$, Alpha $(\alpha)$ e Teta $(\theta)$ (vide Exemplo 2a e 2 b). Cada um dos seis acordes delimita uma seção específica, caracterizada por uma diferença de atmosfera relacionada a específicos gestos musicais. É importante observar que esses acordes são transposições a uma $4^{\text {a }}$ justa superior dos acordes das Cartas Celestes XIII.
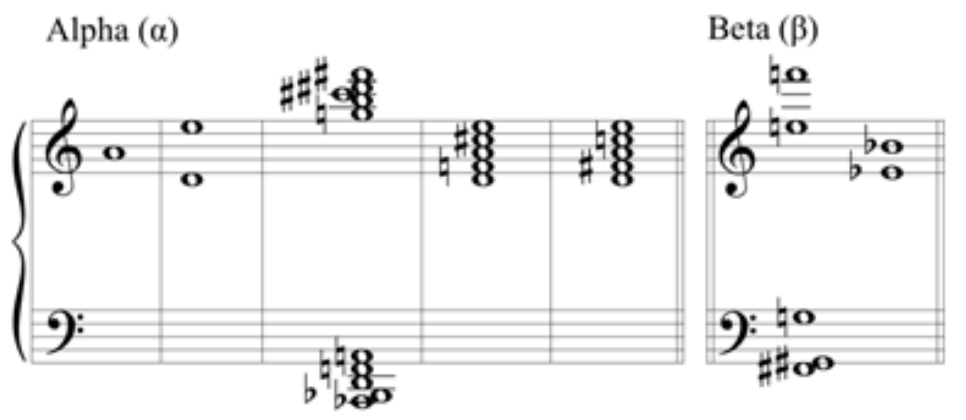

$\operatorname{Gama}(\gamma)$

Exemplo 2a: Almeida Prado: Acordes Alpha $(\alpha)$, Beta $(\beta)$, Gama $(\gamma)$ de Cartas Celestes XIII.

\footnotetext{
${ }^{1}$ As Cartas Celestes I-VI e XIII-XVIII constituem ciclos que têm como elemento comum a presença de acordes baseados nas letras do alfabeto grego, transpostos nas Constelações de cada volume. Prado compôs um catálogo para cada um de tais ciclos, sendo que as Cartas Celestes XIII-XVIII apresentam acordes mais complexos.

2 Tradução nossa.
} 
Delta $(\delta)$

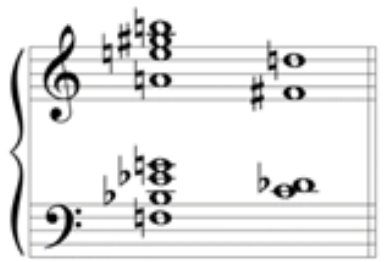

Eta $(\eta)$

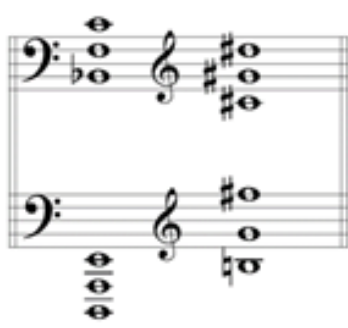

Teta $(\theta)$

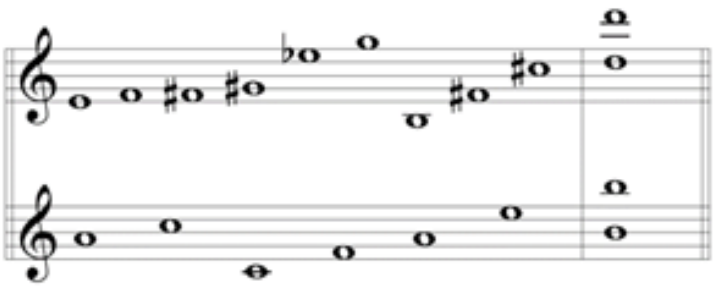

Exemplo 2b: Almeida Prado: Acordes Delta ( $\delta)$, Eta $(\eta)$ e Teta $(\theta)$ de Cartas Celestes XIII

O acorde beta $(\beta)$ caracteriza a primeira seção, que dura 2 compassos:

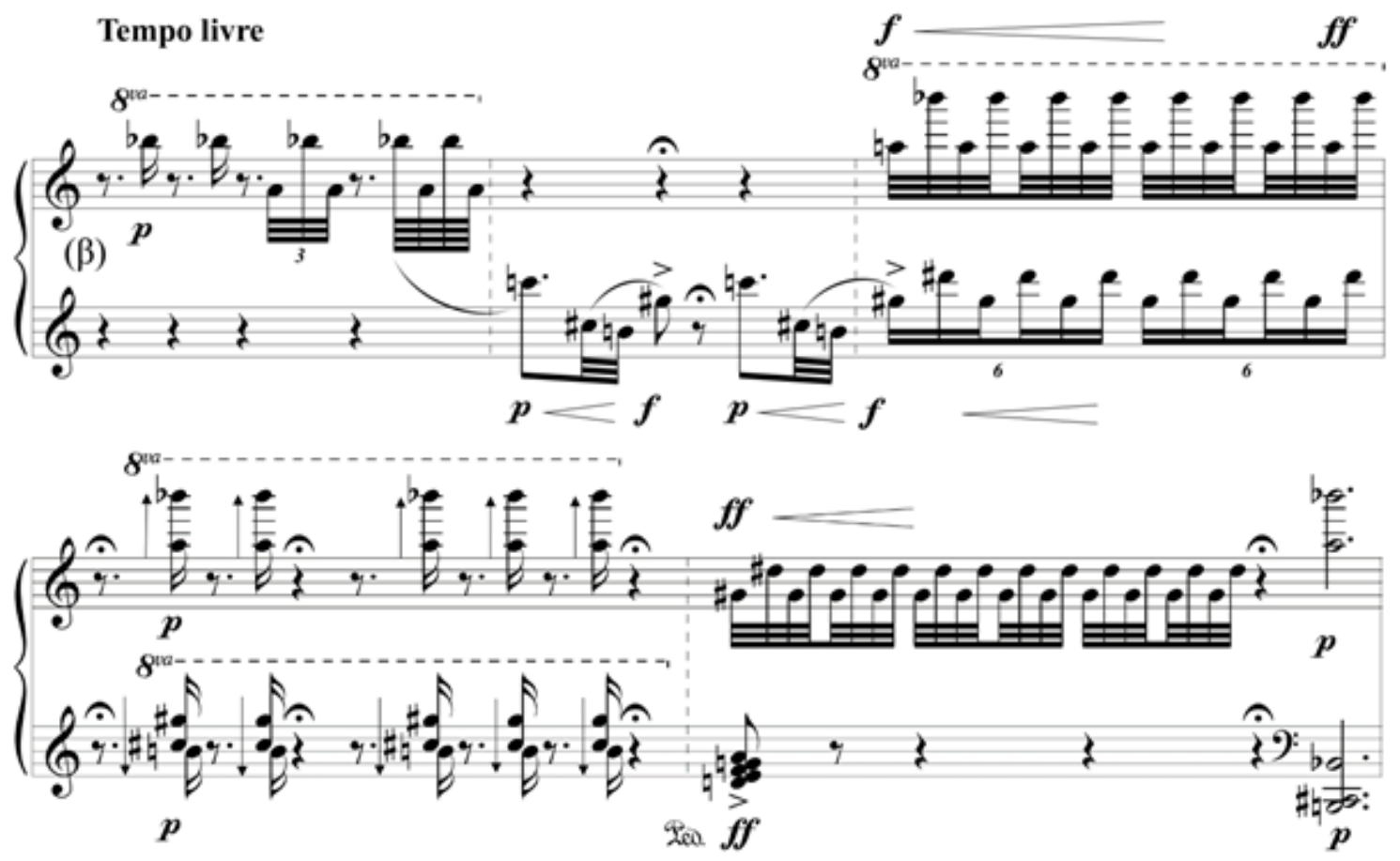

Exemplo 3: Almeida Prado, Cartas Celestes XV (Ave do Paraíso), c. 1-2

Essa seção é marcada pela ressonância do Si bemol, que repetido isoladamente duas vezes é depois acrescido do Lá natural, formando uma 9a Maior, inversão de $2^{a}$ menor. A compactação, decorrente do aumento do número de notas dentro da duração de uma semicolcheia de uma para três e depois para quatro, causa um efeito de condensação da fluidez rítmica, que é interrompida pela nota Dó5 natural, Dó4 sustenido e Si3 sustenido, os três semitons do acorde conduzindo à nota Sol4 sustenido, a segunda nota central da seção, juntamente com o Si bemol. O Sol4 sustenido formará com o Ré5 sustenido uma $5^{\text {a }}$ justa, 
modificando o efeito timbrístico da $9^{a}$ Maior repetida no agudo. O semitom Sol4 sustenido - Lá5 natural é reforçado por serem as primeiras notas audíveis dos acordes arpejados em movimento contrário no compasso 2. A $5^{\mathrm{a}}$ justa reaparece, dessa vez acompanhada por um cluster de notas brancas, antes do repouso. A indicação "Tempo livre", na seção beta $(\beta)$, valoriza o silêncio entre cada nota e recria o barulho de pássaros numa floresta.

A segunda seção utiliza o acorde Gama $(\gamma)$, e vai do compasso 3 ao compasso 6. Almeida Prado requer uma mudança brusca de caráter, exigindo rigor rítmico, através da indicação "Tempo medido":

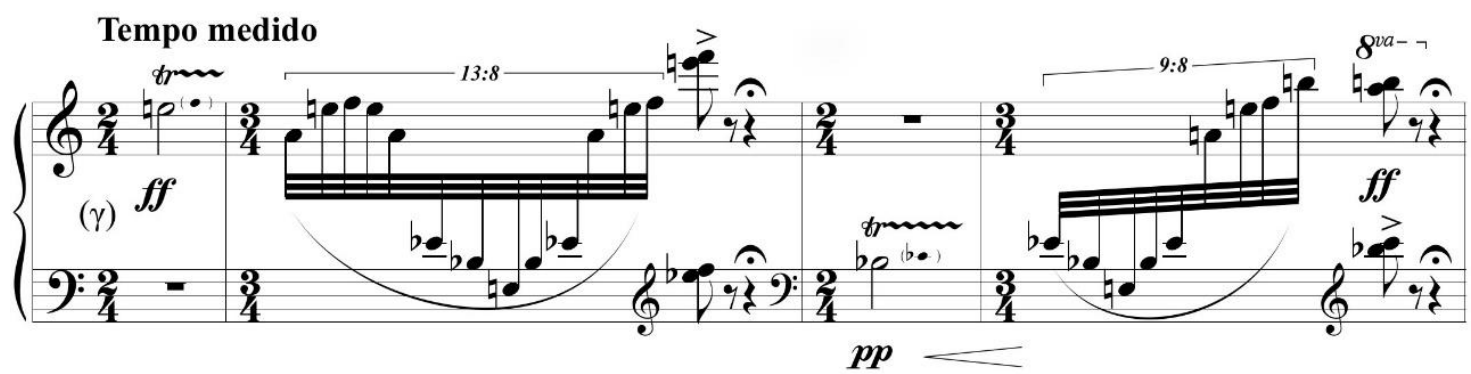

Exemplo 4: Almeida Prado, Cartas Celestes XV, Ave do Paraíso, c. 3-6.

Essa seção é composta de dois gestos, cada um com a duração de dois compassos e iniciado num trinado, que desemboca em um longo arpejo seguido de um acorde de quatro sons, formado por uma $2^{\text {a }}$ Maior na mão esquerda e uma $2^{a}$ menor na mão direita (em seguida transformado em Maior no compasso 4). Separados por um trítono, o primeiro trinado começa pela nota Mi natural e o segundo, pela nota Si bemol.

Aqui vemos a influência de Messiaen quanto à autonomia rítmica. É importante notar e reforçar as indicações contrastantes "Tempo livre" $\mathrm{e}$ "Tempo medido" das seções 1 e 2. Gandelman e Cohen (2006a), em sua edição da Cartilha Rítmica para piano ${ }^{3}$ de Almeida Prado, fazem comentários sobre um exercício (II.32) que aborda essa questão. Nele, a seção em “Tempo livre” apresenta maior variedade de figuras rítmicas, organizadas em grupos separados por barras e fermatas. Já na seção em "tempo medido", o andamento fixado pela indicação metronômica, com "o valor semínima funcionando como unidade de referência temporal" (Gandelman e Cohen 2006b, p. 721) fornece densidade textural estável.

\footnotetext{
${ }^{3}$ Prado compôs a Cartilha Rítmica para piano na década de 1990. Trata-se de uma coleção de 103 exercícios de cunho didático em quatro volumes, que explora muitas das técnicas rítmicas empregadas na música do século $X X$, incluindo os ritmos hindus e gregos desvendados na classe de Messiaen. A Cartilha seria uma "espécie de Czerny dos dias de hoje" (Almeida Prado apud Gandelman e Cohen 2006a, p. 19), porém elaborado de acordo com as diretrizes do ritmo. Cada exercício possui em seu título uma descrição explícita da técnica empregada.
} 
A terceira seção apoia-se no acorde delta ( $\delta$ ) e vai do compasso 7 ao compasso 15. Dois gestos se alternam. O primeiro é composto por dois acordes em bloco na sonoridade $p$ e o segundo é marcado pela repetição insistente de rápidas figuras de fusas com semicolcheias pontuadas nas duas mãos em $f f$ (vide Exemplo 5).

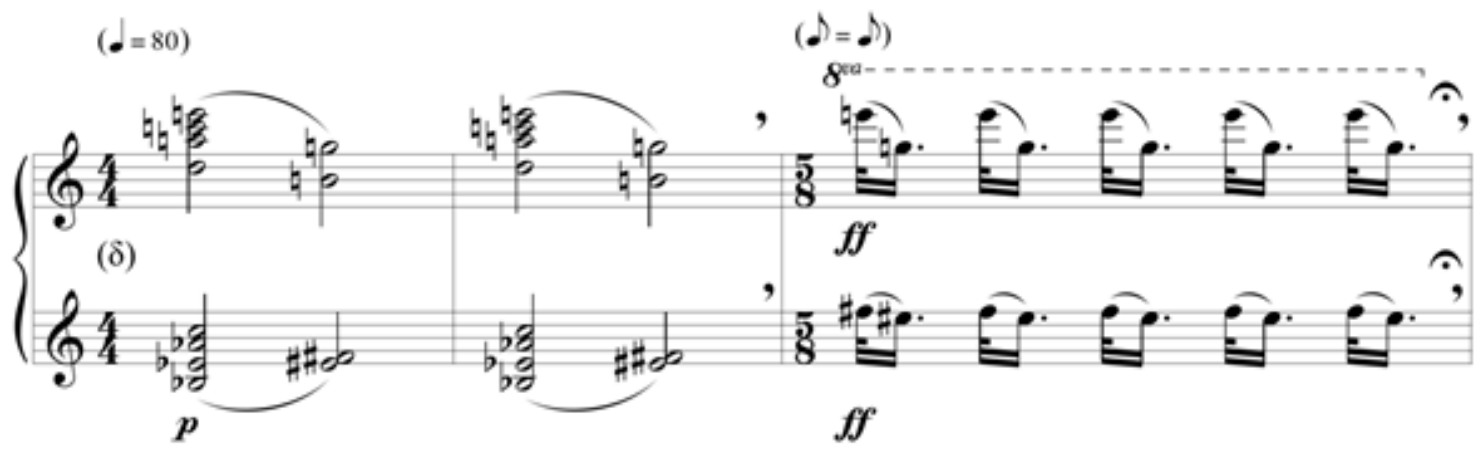

Exemplo 5: Almeida Prado, Cartas Celestes XV (Ave do Paraíso), c. 7-9

As repetições dos dois gestos não são idênticas em número. Na primeira apresentação, o gesto 1 é repetido duas vezes, e o gesto 2 cinco vezes. Na segunda apresentação, o gesto 1 é ouvido apenas uma vez, e o gesto 2 três vezes. Na última apresentação, o gesto 1 é repetido três vezes e o gesto 1 duas vezes, porém intercaladas por uma pausa com fermata. A diferença no número de repetições parece aleatória e, portanto, atribui à seção um caráter de improvisação.

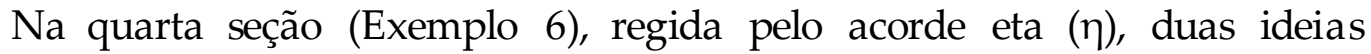
novamente se alternam, porém dessa vez com variantes. A primeira ideia é a repetição de acordes em blocos e a segunda é marcada, como na seção delta $(\delta)$, pela repetição de rápidas figuras no agudo, quatro sons na direita e três na esquerda:

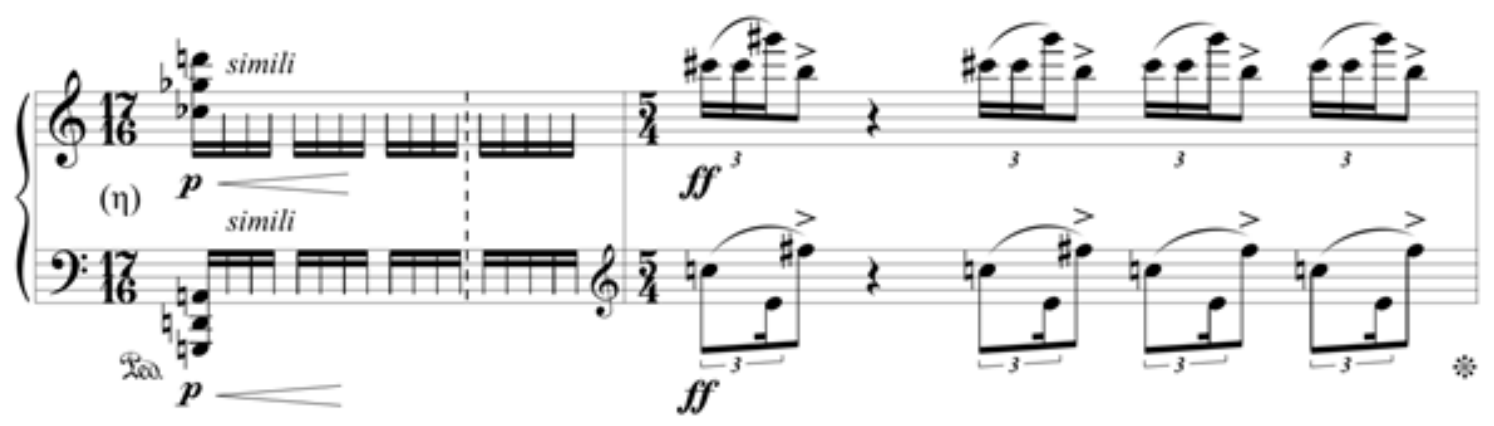

Exemplo 6: Almeida Prado, Cartas Celestes XV (Ave do Paraíso), c. 16-17

Na variante, os acordes em blocos são arpejados e a repetição das notas reduzida a um arpejo em staccato, terminando num trinado no extremo agudo do teclado com um cluster no extremo grave. 
A quinta seção (Exemplo 7) utiliza o acorde alpha $(\alpha)$.
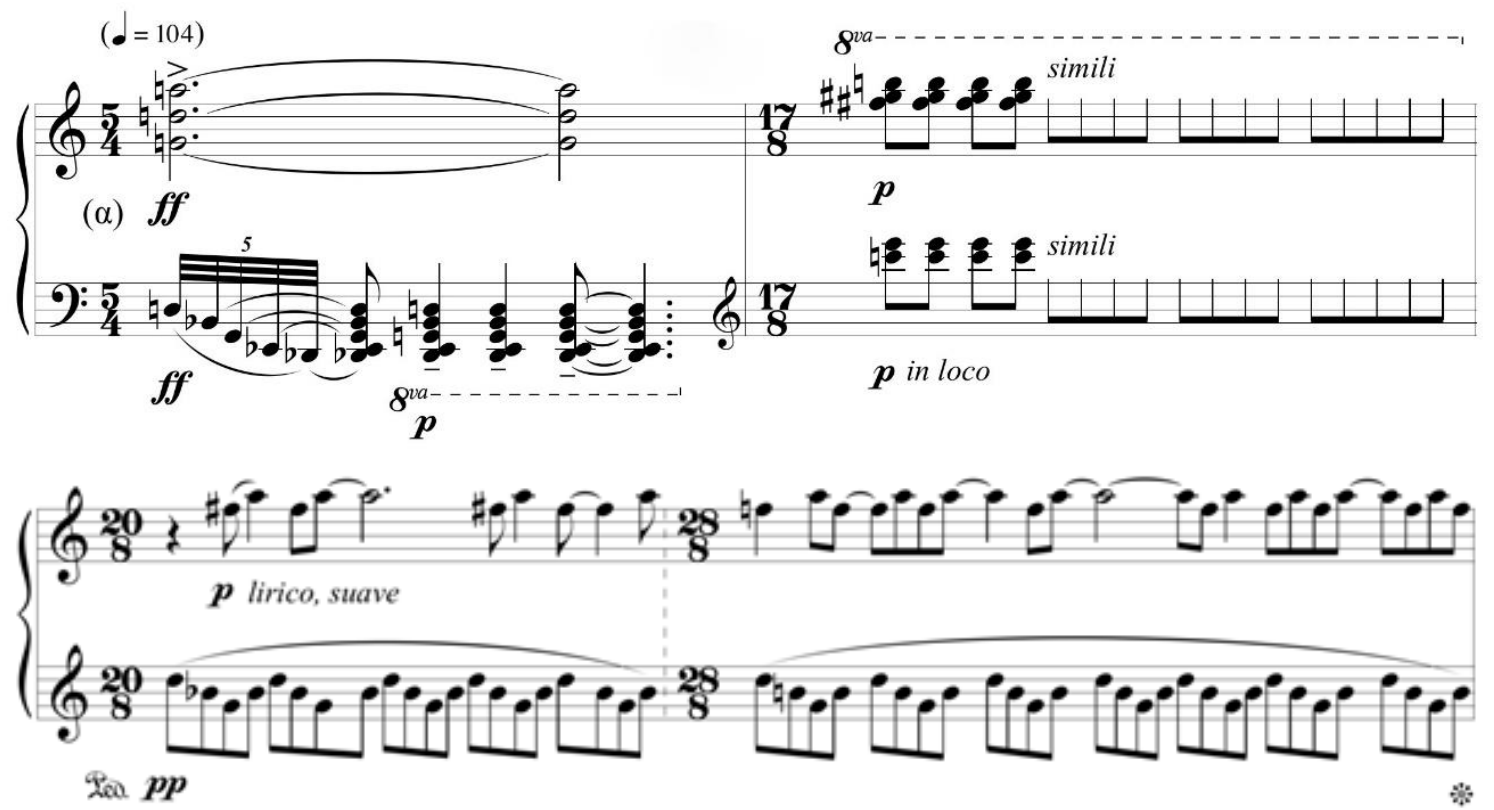

Exemplo 7: Almeida Prado, Cartas Celestes XV (Ave do Paraíso), c. 21-23

O compasso 23, com a indicação "lírico, suave", é o primeiro momento no movimento de ternura e lirismo, e sugere, dentro do cenário interpretativo, o canto de uma ave. Para manter sua simplicidade, sugere-se o emprego de pouco rubato, com um leve decrescendo ao final do compasso, atento à ressonância, num esvair que servirá de preparação para a última seção.

A sexta e última seção (Exemplo 8), de apenas três compassos, é marcada pela indicação "multicolorido!" Nela, o acorde teta $(\theta)$ forma rápidos arpejos cromáticos com ressonância dos baixos Lá4 bequadro, repetido três vezes, Fá3 bequadro e Mi3 bequadro. Repetida inúmeras vezes em accelerando, ela cria um vórtice sonoro que sugere uma aglomeração de aves.

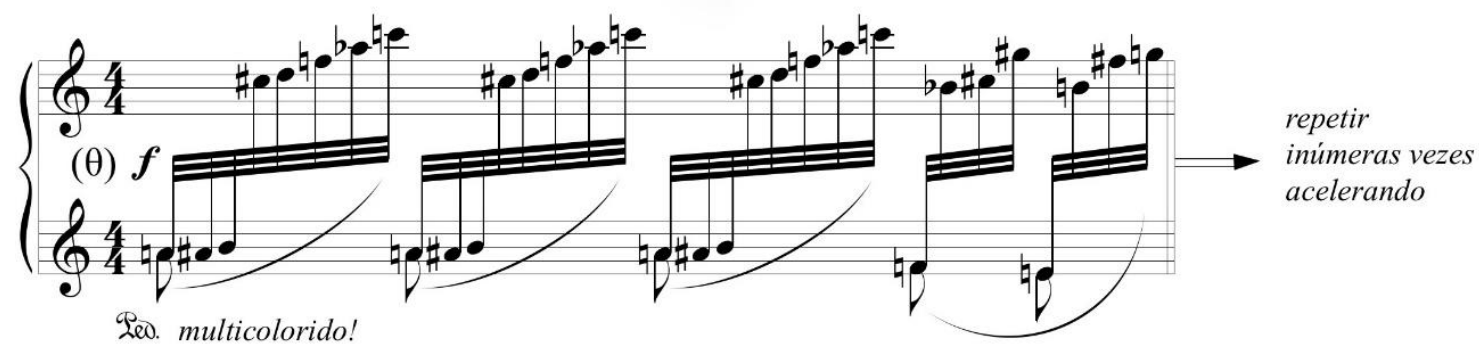

Exemplo 8: Almeida Prado, Cartas Celestes XV (Ave do Paraíso), c. 24 
O movimento termina com duas oitavas em uníssono, em $f f$, na nota Sol bequadro. Essas oitavas são a segunda parte do acorde teta $(\theta)$. Novamente o elemento da surpresa está presente e devem soar como um último guincho.

Percebe-se que Almeida Prado emprega uma multiplicidade de alternâncias métricas e de regiões do teclado. Interpreta-se aqui que o processo de imitação de pássaros e barulhos da natureza é notado através da alternância de texturas mais finas com outras mais densas. Dessa maneira, as texturas mais densas em "Avis Indica" - os acordes em blocos repetidos e arpejados - são os temas simbólicos dentro dos quais, utilizando-se do mesmo material transtonal, porém em textura mais fina e transparente - que são os trinados e grupos rápidos de notas em regiões agudas - escutamos os barulhos dos pássaros e seus apitos e estampidos.

\section{3 - Considerações Finais}

Após uma breve análise do quarto movimento Constelação Ave do Paraíso (Avis Indica), das Cartas Celestes $X V$, notamos a influência dos ideais estéticos de Messiaen que estão diretamente relacionados aos procedimentos composiciona is empregados na obra para piano de Almeida Prado.

Assim como na obra do compositor francês, observamos que a cor sonora é fundamental na estética do compositor brasileiro e é explorada através dos acordes transtonais, apoiados nas variações de agógica e dinâmica que buscam emular novas zonas de ressonâncias. A obra de Almeida Prado é sempre guiada pela gama de riqueza timbrística. Essa ênfase no timbre foi sempre sua principal orientação estética.

Como uma alusão ao som-cor de Messiaen, Almeida Prado comenta em sua tese (1985), na análise dos acordes gregos do primeiro ciclo, a importância do contraste de sombra e luz, da oscilação de luminosidade que cada acorde deve ter, de acordo com a escrita empregada.

O estudo do timbre foi amplamente enriquecido pela análise descritiva do título empregado no movimento, que faz alusão direta aos pássaros, uma grande paixão compartilhada por ambos compositores. A complexidade e liberdade rítmicas presentes no movimento caracterizam também uma grande influência de Messiaen.

A inserção do autor dentro do contexto dos ensinamentos de Messiaen ajudou no entendimento mais profundo do modo de compor de Almeida Prado e no emprego de suas técnicas no seu último período composicional, levando à criação de texturas e cores apropriadas, que muito contribuem para a geração de novas imagens sonoras. 


\section{Referências}

1. Almeida Prado, José Antônio Rezende de. 1985. Cartas Celestes: Uma Uranografia Sonora Geradora de Novos Processos Composicionais. Tese de Doutorado na UNICAMP.

2. 2009. Cartas Celestes XV para piano: O Universo em Expansão.

São Paulo: manuscrito da partitura para piano, (34 p.).

3. Gandelman, Salomea \& Cohen, Sara. 2006a. Cartilharítmicapara piano de Almeida Prado. Rio de Janeiro: Petrobras.

4. 2006b. Tempo fixo e tempo livre na "Cartilha rítmica para piano" de Almeida Prado. In: Anais do XVI Congresso da Associação Nacional de Pesquisa e Pós-graduação em Música (ANPPOM), em Brasília.

5. Grosso, Hideraldo. 1997. Os Prelúdios para Piano de Almeida Prado: Fundamentos para Uma Interpretação. Dissertação de Mestrado na UFRGS.

6. Gazzaneo, Paulo Ricardo. 2011. Trio Marítimo de Almeida Prado: subsídios para interpretação. Dissertação de Mestrado na UNICAMP.

7. Gubernikoff, Carole. 1995. Três compositores brasileiros nos anos 70 e 80: Rodolfo Caesar, Gilberto Mendes e Almeida Prado (relato). In: Anais do VIII Encontro Nacional da ANPPOM, em João Pessoa.

8. Guigue, Didier. 2000. Sobre a estética sonora de Messiaen. In: Revista Opus No7, p. 20-33.

9. Salles, Paulo de Tarso. 2005. Aberturas e impasses: O pós-modernismo na música e seus reflexos no Brasil - 1970-1980. São Paulo: Editora Unesp.

10. Taffarello, Tadeu Moraes. 2010. O percurso da intersecção Olivier Messiaen Almeida Prado: Momentos, La Fauvette des Jardins e Cartas Celestes. Tese de Doutorado na UNICAMP.

11. White, Mel. 2012. Paradise Found. National Geographic Magazine, Official Journal of the National Geographic Society, Vol. 222 no 6, p. 70. 